\title{
Bilateral Extended Nasolabial Flap for Lower Lip and Chin Reconstruction-A Case Report and Review of Literature
}

\author{
Shehla Khan* and Zubair Durrani \\ Department of Oral and Maxillofacial Surgery, Rehman Medical Institute, Peshawar, Pakistan
}

*Corresponding author: Shehla Khan, Department of Oral and Maxillofacial Surgery,

Rehman Medical Institute, Peshawar, Pakistan.

Received Date: March 24, 2021

Published Date: April 23, 2021

\section{Introduction}

Squamous cell carcinoma (SCC) of the lip is the most common malignancy accounting for $25 \%$ of all oral cavity cancers [1]. The lower lip is the most commonly effected site accounting for $90 \%$ of the reported cases with strong male predominance. Most of these cases occur due to its greater exposure to the predisposing factors [2, 3]. Since lip SCC is a transitional zone tumor between skin and the oral mucosa, it acquires characteristics of both [4]. SCC grows through the mucosal surfaces and infiltrates the deep structures in a predictable fashion. Tumors can spread by direct penetration, tracking along the nerves and vascular invasion routes [5]. The defect left by excision of such tumors presents a challenge to the operating surgeon particularly when commissures are also involved. We report such a case in which excision was performed with simultaneous reconstruction using bilateral inferiorly based extended nasolabial flaps.

Keywords: Nasolabial flap; Facial artery ligation; lower lip and chin reconstruction; Plastic and reconstructive surgery; Head and neck oncology

\section{Case Presentation}

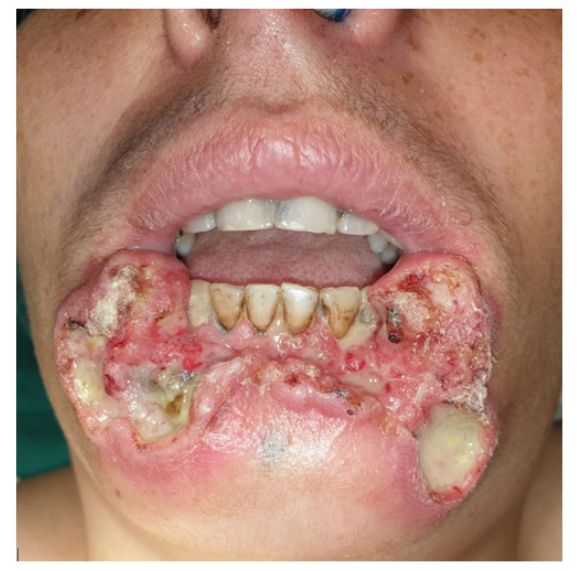

Figure 1 


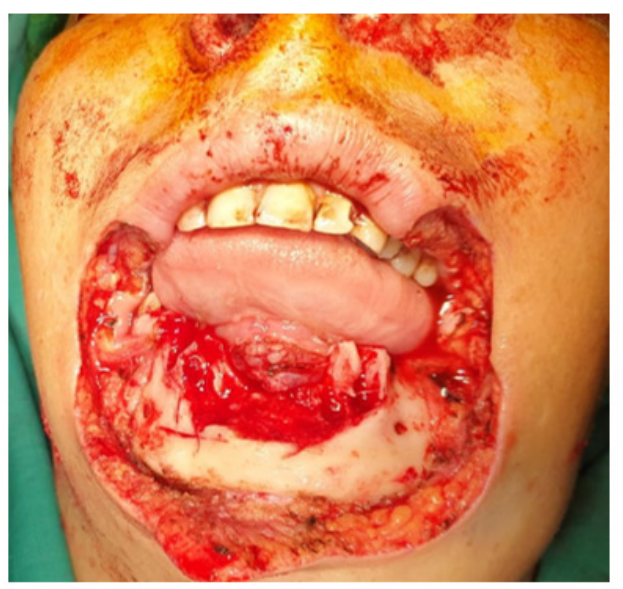

Figure 2

A 30-year-old woman presented with a recurrent fungating squamous cell carcinoma involving her lower lip including bilateral commissures and extending onto the chin area (Figure 1). She had continuous drooling of saliva and inability to eat food properly due to lack of competent seal of the oral aperture. Computed tomography (CT) with contrast showed the erosion of the anterior buccal cortical plate of the mandible. There was no radiologically significant disease in the neck. Patient was admitted and wide local excision was performed with $1 \mathrm{~cm}$ margin and marginal mandibulectomy. Bilateral selective neck dissection (I-III) was also performed with preservation of facial artery. The size of the defect created after excision of the tumor was $6 x 8 \mathrm{~cm}$ (Figure 2).

A bilateral inferiorly based nasolabial flap was marked on both sides 2-3mm lateral to the nasolabial fold. Facial artery was identified with Doppler ultrasonography and its course was marked. An axial pattern flap was raised just above the muscular layer to preserve the facial nerve. The inferiolateral end of the incision was extended laterally upto $2 \mathrm{~cm}$ above the anterioinferior angle of masseter muscle. The medial incision was extended in downward direction to join the lateral border of the defect. The right nasolabial flap was used to reconstruct the resected part of the chin upto the future labio mental fold. Lingual mucosa was then sutured to the inner surface of the flap to recreate labial sulcus. Following this the left nasolabial flap was used to reconstruct the lower lip (Figure 3). Patient was kept on nasogastric feed for one week. Postoperatively there was sensation present to the light touch and pin prick in both flaps. On drinking water, pursing of lower lip was also noted.

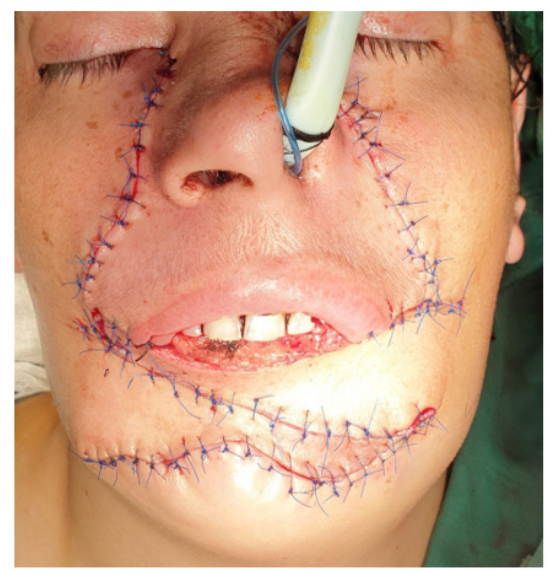

Figure 3

\section{Discussion}

Defects created after tumor excision involving total lower lip and chin can be a great challenge to even the most experienced surgeon to reconstruct. A detailed assessment of the defect, including size, location, depth, extent, inclusion of the nearby subunits, and the effect on function are of paramount importance in determining the success of the reconstruction. Reconstructive goals include restoration of normal anatomy and function like oral competence and lip motion while minimizing secondary deformity and optimizing the aesthetic result. The techniques available for total lip construction include local flaps such as Bernard von Burrow-Webster and nasolabial flap [6, 7]. These flaps have the 
advantage of replacing like tissue with like and low morbidity. They generally produce good functional results and are aesthetically pleasing. Regional flaps like pectoralis major myocutaneous and deltopectoral flap have also been used but are bulky and nonfunctional $[8,9]$. Free microvascular flaps like radial forearm and anterolateral thigh flap have been used with varying variations and success rates $[10,11]$.

In modern literature, nasolabial flap was first described by a German surgeon, John Friedrich Dieffenbach in 1846. Since then, this flap has been used extensively with varying success in reconstruction of orofacial defects $[12,13]$. It can be raised unilaterally or bilaterally and can be designed as superiorly, inferiorly or centrally based pedicle flap. Its feeding vessel is facial artery that after originating from the external carotid passes underneath the posterior belly of digastric muscle and swirls around the submandibular gland before appearing at the anteroinferior border of the masseter muscle. It then travels upwards toward the medial canthus and terminates while anastomosing with ophthalmic branches of internal carotid artery with certain variation [14]. The flap is commonly designed lateral to the nasolabial fold with the medial limit of the flap 2-3mm lateral to this fold [15]. Traditionally, inferiorly based nasolabial flap are raised upto the oral commissure. However, for larger defects especially in cases of total lip chin defects, flap can be extended in downward direction. While generally these flaps are raised as pedicled flaps, difficulty arises when concomitant neck dissection is also planned. In such cases, random pattern flap may be harvested but it might increase the risk of partial or total necrosis particularly when bilateral facial arteries are ligated. Some authors have preserved the facial artery while performing the neck dissection, there is concern, however, that it might increase the risk of recurrence.

Varghese, et al. [16] in a large series of 224 cases performed 234 nasolabial flaps along with 63 functional neck dissections and 82 ipsilateral supraomohyoid neck dissections. 19 patients out of 212 developed either partial or total flap necrosis where facial artery was preserved. While in those cases $(n=12)$ where facial artery was ligated, 2 developed total flap loss and 7 had partial necrosis $(\mathrm{p}=0.0000001)$. A significant difference indicating impact of facial artery ligation on flap survival. Overall, $23.2 \%$ (52) cases developed locoregional recurrence $(p=0.03)$ in this series [16]. Similarly, Wijk, et al. [17] in another case series reported performing 105 flaps in 79 patients, of these 26 were bilateral. In all cases traditional modified radical neck dissection was performed. Partial flap loss was noted in 12 cases while 5 cases developed wound dehiscence. Secondary tumor or local recurrence was seen in $22 \%$ cases [17]. Singh et al, [18] in another case series reported 22 patients where nasolabial flap was harvested along with concomitant neck dissection while preserving the facial artery. In 15 cases, excision of tumor was acheived through intraoral excision while in 7 cases lip split was performed. Additionally, 7 patients received adjuvant radiotherapy. 3 patients developed wound dehiscence and one reported orocutaneous fistula while 1 suffered from local recurrence [18]. Mebed, et al. [19] in another case series of 23 patients, performed 19 nasolabial flaps and 4 facial artery musculomucosal flaps. In all cases, concomitant neck dissection was performed while ligating the facial artery. They reported 2 cases of wound dehiscence and 1 case of partial necrosis [19]. In another study by Ducic, et al. [20] nasolabial performed on 18 patients. 4 of these cases were performed along with ipsilateral radical neck dissection (facial artery ligated). No complication was noted effecting the flaps in this series [20].

The summary of these results along with other are given in (Table 1). A metanalysis of these results show that over all 515 nasolabial flaps were performed. Facial artery was ligated in 163 while preserved in 352. Those cases where facial artery was ligated, $27(16.5 \%)$ developed either partial or complete necrosis but in those where facial artery was preserved, only 13 (3.69\%) developed partial or complete necrosis ( $p<0.001$ ). Overall, 347 concomitant neck dissections were performed in these cases with overall locoregional recurrence rate of $20.7 \%$ (72) cases. It is however not clear that whether risk of neck recurrence increased with facial artery preservation [16-25].

Table 1

\begin{tabular}{|c|c|c|c|c|c|c|c|c|c|c|}
\hline SNO & Study & Cases & Flaps & ND & FL & FP & Dehiscence & Necrosis & Recurrence & OCF \\
\hline 1 & Varghese et al. (2001) [16] & 224 & 234 & 149 & 12 & 212 & - & $9 \mathrm{FL} 13 \mathrm{FP}$ & 52 & 3 \\
\hline 2 & Wijk, et al. (2000) [17] & 79 & $\begin{array}{c}105(26 \\
\text { bilat })\end{array}$ & 79 & 79 & 26 & 5 & 12 partial & 17 & - \\
\hline 3 & Singh, et al. (2012) [18] & 26 & 26 & 22 & 4 & 22 & 3 & - & 1 & 1 \\
\hline 4 & Mebed, et al. (2009) [19] & 23 & $\begin{array}{c}23 \\
4(\mathrm{MM})\end{array}$ & $\begin{array}{c}15 \text { unilateral } 8 \\
\text { bilateral }\end{array}$ & 23 & 0 & 2 & 1 partial & - & \\
\hline 5 & Ducic, et al. (2000) [20] & 18 & 28 & 4 & 4 & 22 & - & - & - & - \\
\hline 6 & Hakeem, et al. (2016) [21] & 25 & 28 & 14 & 14 & 14 & - & - & - & - \\
\hline 7 & $\begin{array}{c}\text { Lazaridis, et al. (1998) } \\
\text { [22] }\end{array}$ & $\begin{array}{c}1514 \\
\text { bilateral }\end{array}$ & 22 & 1 unilateral 1bilateral & 2 & 20 & - & 1 partial & - & - \\
\hline 8 & $\begin{array}{c}\text { Naplitano, et al. (2000) } \\
{[23]}\end{array}$ & 6 & 7 & 5 & 3 & 4 & - & - & - & - \\
\hline
\end{tabular}




\begin{tabular}{|c|c|c|c|c|c|c|c|c|c|}
\hline 9 & Eclardt, et al. (2011) [24] & 22 & $\begin{array}{c}15 \text { uni 7 } \\
\text { bilat }\end{array}$ & 16 & 16 & 13 & - & $\begin{array}{c}1 \text { partial } 1 \\
\text { complete }\end{array}$ & - \\
\hline 10 & Kallapa, et al. (2019) [25] & 25 & 27 & 24 & 24 & 3 & - & 2 partial & 2 \\
\hline
\end{tabular}

ND: Neck Dissection, FL: Facial artery ligation, FP: Fsacial artery preservation, OCF: Orocutaneous fistula.

\section{Conclusion}

Nasolabial flap is a widely harvested flap in head and neck region for local reconstruction. Its width can be a limiting factor but if raised bilaterally, can compensate for it. Extended flaps may be required occasionally for more complex and inferior defects. In such cases where concomitant neck dissection is planned, facial artery ligation may compromise flap survival. Risk of recurrence associated with facial artery preservation is not clear even if it is an elective procedure.

\section{Acknowledgement}

None

\section{Conflict of Interest}

No Conflict of Interest.

\section{References}

1. Zitsch RP, Park CW, Renner GJ, Rea JL (1995) Outcome analysis for lip carcinoma. Otolaryngol Head Neck Surg 113: 589-596.

2. Chen J, Katz RV, Krutchkoff DJ (1992) Lip cancer. Incidence trends in Connecticut, 1935-1985. Cancer 70: 20-25.

3. JGAM de Visscher JG, Grond AJ, Otter R (2002) Lip carcinoma. A review. Ned Tijdschr Tandheelkd 109: 391-395.

4. Geraud C, Koenen W, Neumayr L (2012) Lip cancer: retrospective analysis of 181 cases. J Dtsch Dermatol Ges (2012) 10(2): 121-127.

5. David LL (2006) Tumors of the Lips, Oral Cavity and Oropharynx. In Plastic Surgery (2 ${ }^{\text {nd }}$ Edn.), Mathes SJ Philadelphia (Ed.), Saunders Elsevier, PP: 159-180.

6. Denadai R (2015) Use of Bernard-Webster flap for lower lip reconstruction after excision of squamous cell carcinoma. Rev Bras Cir Plást 30(1): 8-17

7. Gupta S (2013) A new technique for one-stage total lower lip reconstruction: Achieving the perfect balance. Can J Plast Surg 21(1): 57-61.

8. Elfaki H, Rezeq A, Eldeib M (1994) Reconstruction of chin and lower lip using bilateral segmental pectoralis major myocutaneous flap with functional support. Eur J Plast Surg 17: 212-214.

9. Emerick KS (2020) Free flap reconstruction of the lip. Operative Techniques in Otolaryngology-Head and Neck Surgery. 31(1): P26-32.

10. Parisa F, Cinqiz R, Mahammad D (2016) The Using of Cervical and Deltopectoral Flaps in the Reconstruction Surgery of Head and Neck Area. Adv Dent \& Oral Health 1(5): 555572.
11. Bali ZU, Ozkan B, Parspancı A, Kececi Y, Yoleri L (2020) Reconstruction of lower lip defects with free super-thin anterolateral thigh flap. Microsurgery 1-7.

12. Thornton JF, Weathers WM (2008) Nasolabial flap for nasal tip reconstruction. Plast Reconstr Surg 122(3): 775-781.

13. Rao JK, Shende KS (2016) Overview of Local Flaps of the Face for Reconstruction of Cutaneous Malignancies: Single Institutional Experience of Seventy Cases 9(4): 220-225

14. Furukawa M, Mathes DW, Anzai Y (2013) Evaluation of the facial artery on computed tomographic angiography using 64-slice multidetector computed tomography: implications for facial reconstruction in plastic surgery. Plast Reconstr Surg 131(3): 526-535.

15. H Bi, X Xing, J Li (2014) Nasolabial-alar crease: a natural line to facilitate transposition of the nasolabial flap for lower nasal reconstruction. Ann Plastic Surg 73: 520-524.

16. Varghese (2001) Nasolabial flaps in oral reconstruction: an analysis of 224 cases. Br J Plast Surg 54(6): P499-503.

17.Van Wijk MP, Damen A, Nauta JM, Lichtendahl DHE, Dhar BK (2000) Reconstruction of the anterior floor of the mouth with the inferiorly based nasolabial flap. Eur J Plast Surg 23: 200-203.

18. Singh (2012) Nasolabial flap reconstruction in oral cancer. World J Surg Oncol 10: 227.

19. Mebed AH (2009) Critical appraisal of nasolabial flap for reconstruction of the oral cavity defcets in cancer patients. J Egypt Natl Canc Inst 21(1): 33-42.

20. Ducic Y, Burye M (2000) Nasolabial flap reconstruction of oral cavity defects: a report of 18 cases. J Oral Maxillofac Surg 58: 1104-1108.

21. Hakeem AH, Hakeem IH, Wani FJ (2016) Inferiorly based nasolabial flap for reconstruction of the moderate to large defects of lips following cancer resection. Eur J Plast Surg 39: 187-192.

22. Lazaridis N, Zouloumis L, Venetis G, Karakasis D (1998) The inferiorly and superiorly based nasolabial flap for the reconstruction of moderatesized oronasal defects. J Oral Maxillofac Surg (11):1255-1559.

23. Napolitano M, Mast BA (2001) The nasolabial flap revisited as an adjunct to floor-of-mouth reconstruction. Ann Plast Surg 46(3): 265-268.

24. Eckardt Andre M (2011) Reconstruction of oral mucosal defects using the nasolabial flap: clinical experience with 22 patients. Head Neck Oncol 3: 28.

25. Kallappa S, Shah N (2019) Outcome of Nasolabial Flap in the Reconstruction of Head and Neck Defects. Indian J Surg Oncol 10: 577581 